\title{
DETERMINING WORST-CASE FATIGUE THRESHOLDS FOR GRAIN-BRIDGING CERAMICS
}

\author{
J. J. Kruzic, R. Yuan, R. M. Cannon, R. O. Ritchie \\ Materials Sciences Division, Lawrence Berkeley National Laboratory, and \\ Department of Materials Science and Engineering, University of California, Berkeley, CA 94720
}

\begin{abstract}
A method for determining worst-case cyclic fatigue thresholds in grain-bridging ceramics by quantifying the role of bridging is demonstrated for a model alumina. Crack-growth properties for both long and short $(<2 \mathrm{~mm})$ cracks emanating from machined notches (root radii, $\rho \sim 15$ $150 \mu \mathrm{m})$ were investigated. When compared as a function of the applied stress-intensity range $(\Delta K)$, growth rates $(d a / d N)$ were far higher and fatigue thresholds $\Delta K_{\mathrm{TH}}$ were markedly lower with short cracks, with growth being observable at the lowest driving forces for short cracks emanating from razor micronotches $(\rho \approx 15 \mu \mathrm{m})$. For growth rates $<10^{-8} \mathrm{~m} / \mathrm{cycle}$, $d a / d N$ vs. $\Delta K$ data for short cracks merged with the steady-state data for long cracks after $\sim 2 \mathrm{~mm}$ of extension. This value corresponds well to the measured crack-bridging zone length for long fatigue cracks grown near $\Delta K_{\mathrm{TH}}$. The crack-tip shielding contribution due to bridging was quantified using multi-cutting compliance and crack-opening profile techniques. Bridging stress-intensity factors were computed and subtracted from applied stress intensities to estimate an effective, near-tip driving force, $\Delta K_{\text {eff. }}$ These results, in terms of $\Delta K_{\text {eff, provided a lower }}$ threshold below which both long and short cracks are not observed to propagate and an estimate of the intrinsic toughness for the start of the R-curve. Such results quantitatively affirm that the reduced role of grain bridging is a primary source of the transient behavior of short cracks in grain-bridging alumina-based ceramics under cyclic loading. These methods are additionally applied to estimate the worst-case fatigue threshold and intrinsic toughness of a self-reinforced $\mathrm{SiC}$ based ceramic, for which direct testing at small crack sizes has been prohibitively difficult.
\end{abstract}

\section{Introduction}

In order to prolong the fatigue lifetimes of grain-bridging ceramics, the driving force (e.g., stress-intensity range, $\Delta K$ ) experienced by incipient flaws must remain below the fatigue threshold for virtually the entire service life. This is due to the high dependence of the fatiguecrack growth rates, $d a / d N$, on $\Delta K$, which causes fatigue cracks to grow rapidly to criticality once growth has initiated. An important factor in defining such thresholds is the role of crack size. Although the principle of similitude in fracture mechanics states that two cracks, regardless of their size, will behave in identical fashion provided they are subjected to the same stress intensity (1), in reality crack size effects are observed in many materials, including grainbridging ceramics, for both the toughness $(2,3)$ and fatigue (4-6) behavior. For toughness, rising crack resistance with crack extension (R-curve behavior) is observed, while in fatigue, short or small cracks exhibit lower fatigue thresholds and higher fatigue-crack growth rates than corresponding long cracks. Short or small cracks are defined as cracks that are small compared to: (i) the scale of microstructure (microstructurally small), (ii) the extent of local inelasticity (mechanically short/small), or (iii) the extent of crack-tip shielding (e.g., bridging, closure) in the crack wake (functionally short/small), where short cracks are small relative to crack length and small cracks are small in all dimensions (6). In grain-bridging ceramics, which derive their toughening from grain bridging in the crack wake, crack-size effects are particularly significant as critical crack sizes are often far smaller than the length of the steady-state bridging zones. 
Consequently, to effectively design ceramic components with adequate fatigue lives, the fatigue thresholds at relevant crack sizes must be known.

Unfortunately, for many ceramic materials of interest, i.e., self-reinforced $\mathrm{Si}_{3} \mathrm{~N}_{4}$ and $\mathrm{SiC}$, bridging zones are too short (a few hundred micrometers) to allow convenient direct fatigue testing using functionally short or small cracks. Indeed, when $\geq 250 \mu \mathrm{m}$ long Vickers indent cracks were used in a self-reinforced $\mathrm{SiC}$, it was found that once the effects of the residual stresses due to the indents were taken into account, there was no effect of crack size on growth rates (7). Clearly, testing smaller cracks is necessary to observe such effects. However, an alternative approach to estimating short crack fatigue thresholds is presented here whereby the role of grain bridging is quantified and that information is used to predict the behavior of functionally-short cracks based on long crack results. To affirm this methodology, a commercial alumina was chosen as a model material because its large, millimeter-scale, bridging zones permit both direct short crack experiments, and the quantification of bridging, allowing experimental results to be compared to the predicted short crack fatigue thresholds. Additionally, this methodology is then applied to a self-reinforced SiC ceramic where functionally short crack data have not been attainable to date.

\section{Procedures}

This study was performed primarily on a commercial Coors AD995 alumina $(99.5 \%$ pure, $\geq$ $98 \%$ dense), with a variable grain size ranging from $\sim 1$ to $50 \mu \mathrm{m}$ and a nominal (average) grain size of $18 \mu \mathrm{m}$. While most grains are $<10 \mu \mathrm{m}$ in size, the majority of the material volume comprises grains in the $15-35 \mu \mathrm{m}$ range, with a significant volume fraction arising from even larger grains (5). Additionally, an in situ toughened silicon carbide (5ABC-SiC), made by mixing $\beta$-SiC powder with $5 \mathrm{wt} . \% \mathrm{Al}, 0.6 \mathrm{wt} . \% \mathrm{~B}$ and $2 \mathrm{wt} . \% \mathrm{C}$ and hot pressing (50 MPa) for $1 \mathrm{hr}$ at $1900^{\circ} \mathrm{C}$ in a flowing argon environment, was tested similarly. The microstructure has a mixture of elongated grains, $\sim 20 \pm 6 \mu \mathrm{m}$ long and $\sim 0.8 \pm 0.3 \mu \mathrm{m}$ wide, and equiaxed grains $\sim 0.6 \pm 0.2 \mu \mathrm{m}$ in size. The phase composition consists of $21 \% 6 \mathrm{H}, 11 \% 4 \mathrm{H}$, and $67 \% 3 \mathrm{C}$, with the $3 \mathrm{C}$ phase typically corresponding to equiaxed grains.

Tests were performed using $3 \mathrm{~mm}$ thick, $17 \mathrm{~mm}$ wide, compact-tension $\mathrm{C}(\mathrm{T})$ specimens of alumina, and $3 \mathrm{~mm}$ thick, $28 \mathrm{~mm}$ wide disk-shaped compact-tension DC(T) specimens of SiC. Typical diamond saw-cut notches had root radii, $\rho$, ranging from $\sim 75$ to $150 \mu \mathrm{m}$, while razor micronotches $(\rho \approx 15 \mu \mathrm{m})$, used for some alumina short crack tests, were made by repeatedly rubbing a razor blade over the notch in the presence of a $1 \mu \mathrm{m}$ diamond slurry.

As both materials demonstrate rising R-curve behavior, this was measured to evaluate the fracture resistance in terms of the stress intensity, $K$, under a monotonically increasing load. Cyclic fatigue-crack growth rates, $d a / d N$, for long cracks $\left(\Delta a_{\mathrm{f}}>2 \mathrm{~mm}\right.$, where $\Delta a_{\mathrm{f}}$ is the amount of crack extension from the notch) were measured in room air $\left(25^{\circ} \mathrm{C}, 20-40 \%\right.$ relative humidity) in general accordance with ASTM standard E647, with some modifications for brittle and bridging materials (5). Tests were conducted at a frequency of $25 \mathrm{~Hz}$ (sine wave) using servo-hydraulic testing machines at a constant load ratio (ratio of minimum to maximum loads) of $R=0.1$. Crack lengths, $a$, were continuously monitored using back-face strain compliance techniques $(8,9)$, and crack-driving forces were assessed using the stress-intensity range, $\Delta K=$

$K_{\max }-K_{\min }$. Fatigue thresholds, $\Delta K_{\mathrm{TH}}$, were operationally defined as the minimum applied $\Delta K$ for which $d a / d N \leq 10^{-10} \mathrm{~m} /$ cycle. Continuous load adjustment was used to maintain a $\Delta K$ gradient $(=1 / \Delta K[d \Delta K / d a])$ of $\pm 0.08-0.1 \mathrm{~mm}^{-1}$. Ideally, this rate of change in $\Delta K$ would be sufficiently slow to allow the crack-bridging levels to adjust to the current $\Delta K$ level; however, for AD995 alumina, which has millimeter-scale bridging zones, this was only achieved for $d a / d N \leq 10^{-8} \mathrm{~m} /$ cycle $(5)$. In alumina, short crack $\left(\Delta a_{\mathrm{f}}<2 \mathrm{~mm}\right)$ data were recorded for the first $\sim 2 \mathrm{~mm}$ of crack growth from the notch, where $2 \mathrm{~mm}$ is the crack length beyond which nonsteady-state growth rates were no longer observed. Although the notches have an effect on the 
stress intensity for very short cracks, this effect only dominates for $\Delta a_{\mathrm{f}}<\rho / 6$, and after $\Delta a_{\mathrm{f}} \geq \rho$ the notch effects have completely diminished (10). For short crack fatigue tests, data collection did not begin until $\Delta a_{\mathrm{f}}>2 \rho / 3$, and thus notch corrections were unnecessary.

Crack-opening profile, COP, measurements were used either alone or with the results of multi-cutting compliance experiments to estimate the bridging stress distribution, $\sigma_{\text {br }}(x)$, as described in ref. (5). Such measurements for near-threshold fatigue cracks $\left(d a / d N<7 \times 10^{-10}\right.$ $\mathrm{m}$ /cycle) were made on specimens loaded in situ in a field-emission scanning electron microscope (FESEM). Each sample was loaded to a driving force $\sim 10-20 \%$ less than the measured $K_{\max }$ at the long crack threshold, which were 3.0 for $\mathrm{Al}_{2} \mathrm{O}_{3}$ and $6.2 \mathrm{MPa} \sqrt{\mathrm{m}}$ for $\mathrm{SiC}$.

For alumina, a multi-cutting compliance technique $(5,11)$ was used to evaluate the bridging zone by incrementally cutting out the crack while measuring the sample compliance, $C_{\mathrm{u}}$, via back-face strain gauges after each increment. If active bridges are eliminated from the crack wake, an increase in the compliance is observed, and the grain-bridging zone length, $L$, is determined from the notch length where the compliance begins to increase. Additionally, the normalized grain-bridging stress distribution, $\sigma_{\mathrm{br}}(x) / \sigma_{\max }$, may be computed from the multicutting compliance data. When the bridging-zone length is appreciably smaller than relevant sample dimensions, it has been shown that (11):

$$
\frac{\sigma_{b r}(x)}{\sigma_{\max }}=-\frac{C^{2}(a) C_{\mathrm{u}}^{\prime}(x)}{C^{\prime}(a) C_{\mathrm{u}}^{2}(x)}
$$

where $C(a)$ is the traction free compliance, $C_{\mathrm{u}}(x)$ is the compliance after cutting to the position $x$ measured from the load line, and $C^{\prime}(z)=\mathrm{d} C(z) / \mathrm{d} z$. The grain-bridging stress distribution obtained from Eq. 1 is normalized by the factor $\sigma_{\max }$, the maximum bridging stress at the crack tip. Using the normalized bridging stress distribution obtained from Eq. 1, $\sigma_{\max }$ may be determined from the measured COP, as described below.

For a known set of opening displacements, $\sigma_{b r}(x)$ is solved from the integral equation (12):

$$
\frac{1}{E^{\prime}} \int_{0}^{a} \int_{\max \left(x, x^{\prime}\right)}^{a} h\left(a^{\prime}, x\right) h\left(a^{\prime}, x^{\prime}\right) \sigma_{\mathrm{br}}\left(x^{\prime}\right) d a^{\prime} d x^{\prime}=u_{\mathrm{tot}}-u_{\mathrm{app}}
$$

where $E^{\prime}$ is Young's modulus ( $E$ in plane stress, $E /\left(1-v^{2}\right)$ in plane strain, $v$ is Poisson's ratio), and $x$ is the position of interest with origin at the load line. The weight function, $h$, is geometry specific and has been derived for the $\mathrm{C}(\mathrm{T})$ and $\mathrm{DC}(\mathrm{T})$ specimens as (13):

$$
h=\sqrt{\frac{2}{\pi a}} \frac{1}{\sqrt{1-x / a}}\left[1+\sum_{(v, \mu)} \frac{A_{v \mu}(a / W)^{\mu}}{(1-a / W)^{3 / 2}}(1-x / a)^{v+1}\right]
$$

where the coefficients $A_{v \mu}$ for each sample may be found in ref. (13). While the half crack opening, $u_{\text {tot}}$, is measured directly from the sample, the displacements due to the applied load for a traction free crack, $u_{\mathrm{app}}$, are calculated for the applied driving force, $K_{\mathrm{app}}$, as (14):

$$
u_{\mathrm{app}}=\frac{1}{E^{\prime}} \int_{x}^{a} K_{\mathrm{app}}\left(a^{\prime}\right) h\left(a^{\prime}, x\right) d a^{\prime}
$$

For alumina, the normalized stress distribution from Eq. 1 was substituted into Eq. 2 which was then solved; $\sigma_{\max }$ was determined from a least-squares fit to the experimental data.

For $5 \mathrm{ABC}-\mathrm{SiC}$, to facilitate the solution of Eq. 2 without multi-cutting data, a strainsoftening bridging stress distribution was chosen a priori $(5,15,16)$ as:

$$
\sigma_{\mathrm{br}}=\sigma_{\text {max }}\left(1-\frac{a-x}{L}\right)^{n}
$$

Where $n$ describes the shape of the bridging stress distribution. Since $L$ was unknown for the $\mathrm{SiC}$ specimen, it was set to the maximum extent of data collected, i.e., $1.5 \mathrm{~mm}$. The optimal values of $\sigma_{\max }$ and $n$ were those that gave a computed crack-opening profile nearest that measured experimentally using the least-squares method. Values of the modulus and Poisson's ratio were taken, respectively, as $372 \mathrm{GPa}$ and 0.22 for alumina, and $400 \mathrm{GPa}$ and 0.25 for SiC. 

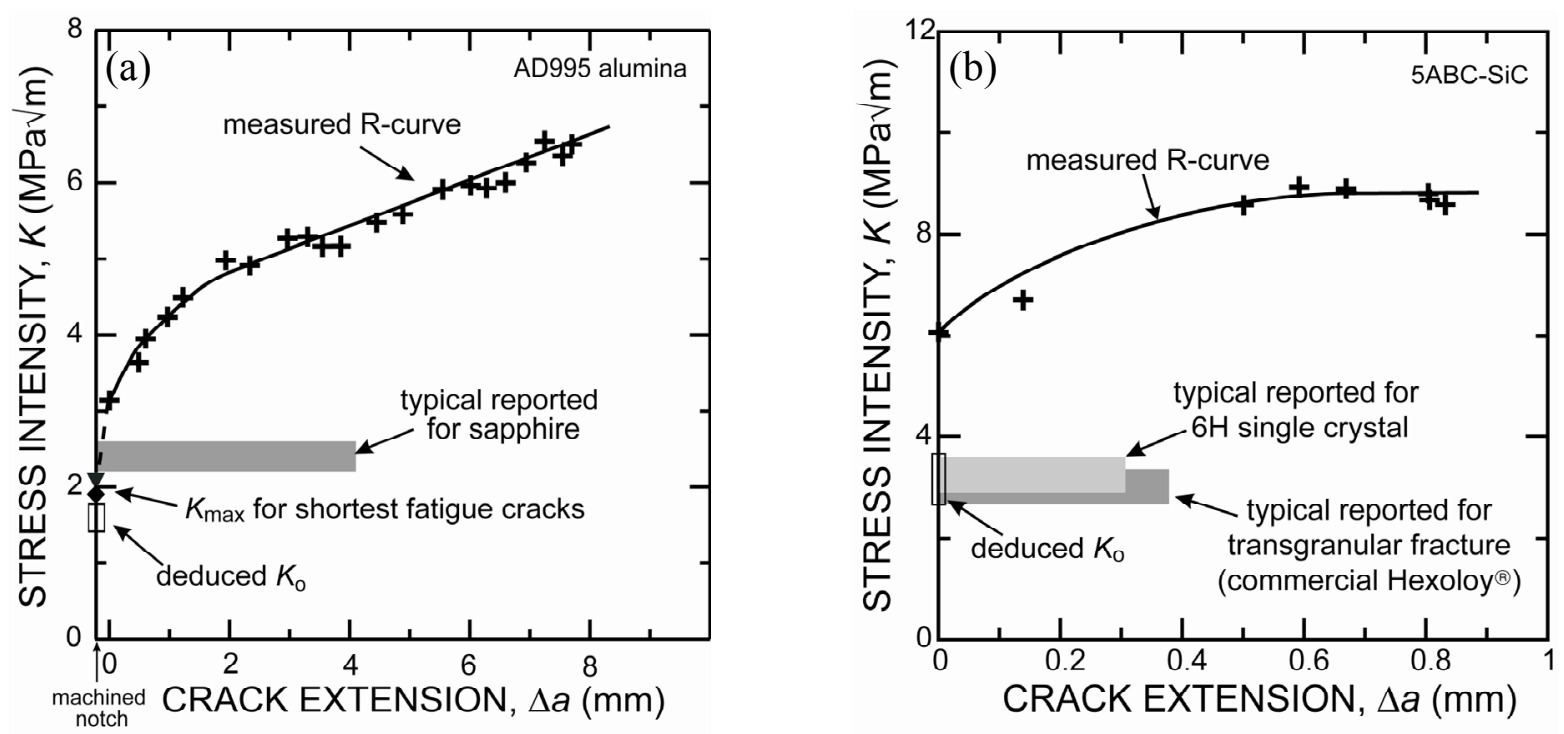

Figure 1: R-curves for (a) alumina and (b) $5 \mathrm{ABC}-\mathrm{SiC}$. The alumina sample had an initial fatigue pre-crack only $230 \mu \mathrm{m}$ long, while for $5 \mathrm{ABC}-\mathrm{SiC}$, the R-curve was initiated from a near-threshold long fatigue crack, due to difficulties with crack initiation.

\section{Results}

Measured R-curve data for AD995 alumina and 5ABC-SiC are shown in Figs. 1a and b, respectively. For alumina, an initial toughness of $K_{\mathrm{i}} \approx 3 \mathrm{MPa} \sqrt{\mathrm{m}}$ was measured at crack initiation from a $230 \mu \mathrm{m}$ long fatigue pre-crack emanating from the machined notch, with rising R-curve behavior observed after crack extensions as large as $8 \mathrm{~mm}$ up to $K_{\mathrm{R}}>6 \mathrm{MPa} \sqrt{\mathrm{m}}$. Due to the small specimen size (width $W \approx 17 \mathrm{~mm}$ ) and large bridging-zone length $(>8 \mathrm{~mm})$ for the alumina, a steady-state (plateau) toughness, $K_{\mathrm{ss}}$, could not be obtained. For $5 \mathrm{ABC}-\mathrm{SiC}$, the Rcurve rises from $K_{\mathrm{i}} \approx 6 \mathrm{MPa} \sqrt{\mathrm{m}}$ to $K_{\mathrm{ss}} \approx 9 \mathrm{MPa} \sqrt{\mathrm{m}}$ after a few hundred micrometers of crack extension from a near-threshold fatigue pre-crack, several millimeters in length.

Fatigue-crack growth rates for long $\left(\Delta a_{\mathrm{f}}>2 \mathrm{~mm}\right)$ and short $\left(\Delta a_{\mathrm{f}}<2 \mathrm{~mm}\right)$ cracks in AD995 alumina are presented in Fig. $2 \mathrm{a}$ as a function of the applied $\Delta K$; corresponding long crack results for 5ABC-SiC are in Fig. 2b. In Fig. 2a, short cracks display quite different behavior from long cracks. Specifically, for cracks $100 \mu \mathrm{m}$ to $2 \mathrm{~mm}$ in length at wider notches:

- growth rates exhibited a similar power-law dependence on the applied $\Delta K$ level with $m \sim 90$
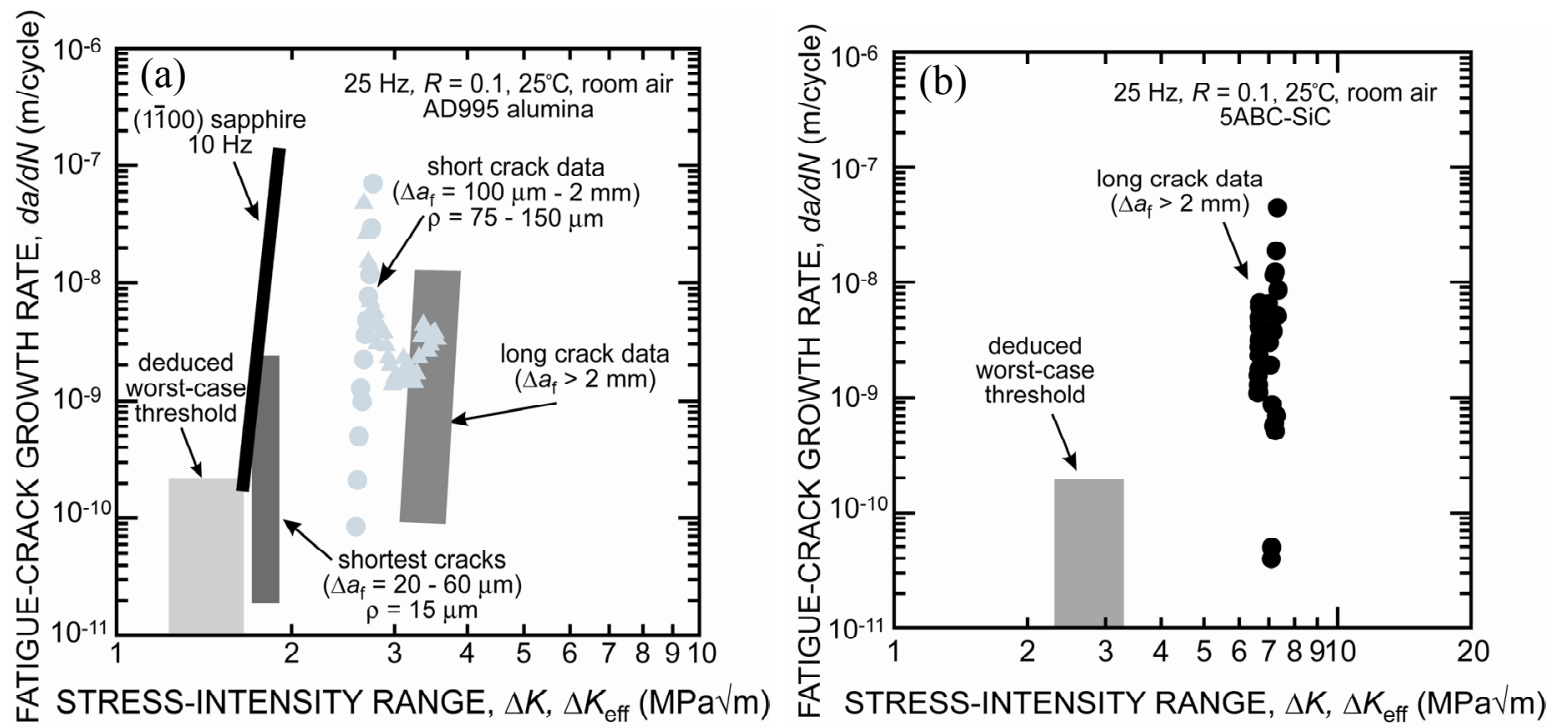

Figure 2: Fatigue results for (a) alumina and (b) 5ABC-SiC. Also shown are the worst-case fatigue thresholds deduced from the crack opening and multi-cutting compliance data. 

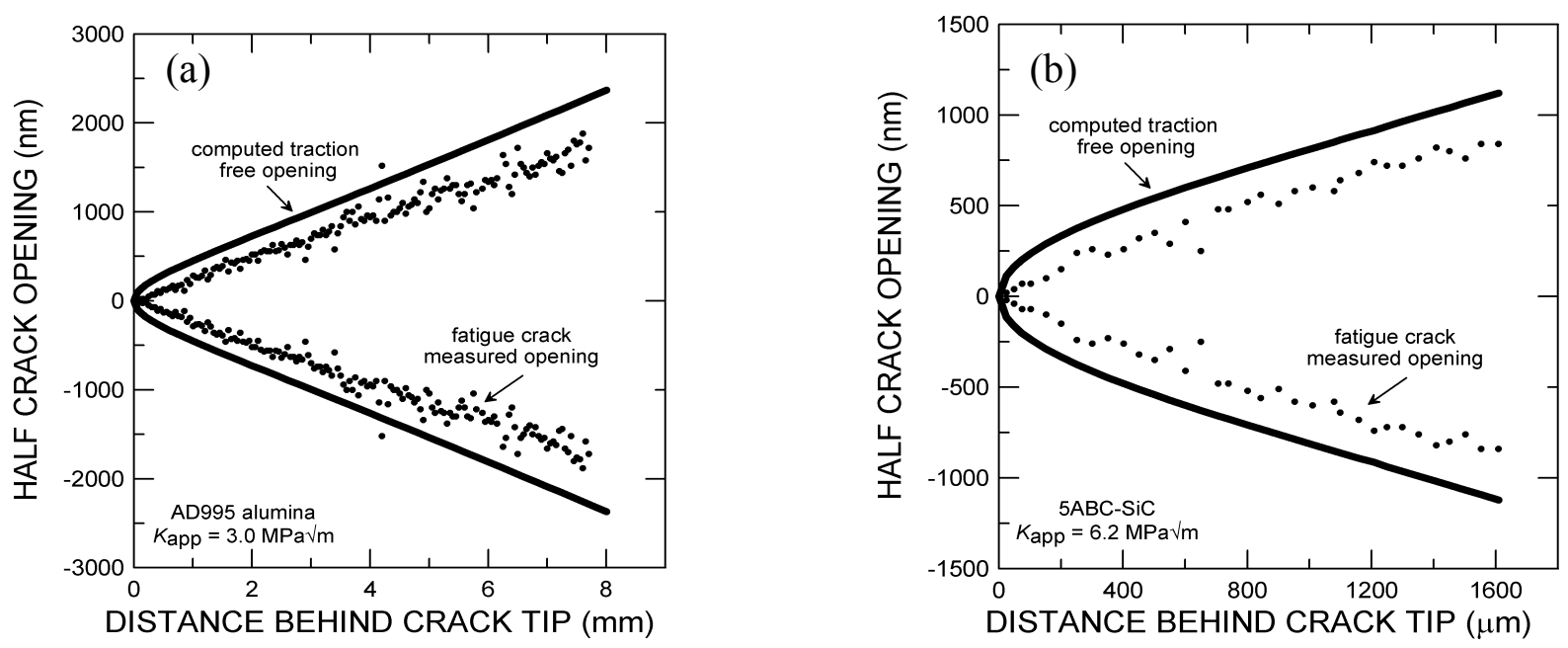

Figure 3: Measured crack opening profiles for (a) alumina and (b) 5ABC-SiC. Also shown are the traction-free crack-opening profiles calculated using Eq. 4 . Note the difference in length scales behind the tip between alumina and SiC.

under decreasing $\Delta K$ conditions; however, the growth-rate curve, and hence $\Delta K_{\mathrm{TH}}$ threshold, were displaced to values $15-25 \%$ lower than for corresponding long cracks.

- growth rates initially decreased before finally increasing and merging with the long crack data under increasing $\Delta K$ conditions. This behavior, which is characteristic of short fatigue cracks in metallic materials (4), resulted in a V-shaped $\mathrm{d} a / \mathrm{d} N-\Delta K$ curve, with short crack data only merging with long crack data after $\sim 2 \mathrm{~mm}$ of growth.

Cracks emanating from razor micronotches grew at even lower driving forces, with crack growth occurring at $\Delta K=1.7-1.9 \mathrm{MPa} \sqrt{\mathrm{m}}$; when the cracks reached an average crack length of $\sim 60 \mu \mathrm{m}$ (as detected by compliance measurements), they had essentially arrested.

Figs. $3 \mathrm{a}$ and $\mathrm{b}$ show the measured crack-opening profiles of near-threshold fatigue cracks in alumina and $\mathrm{SiC}$, respectively. Also shown are the crack-opening profiles for a traction-free crack computed using Eq. 4. It is apparent that, due to bridging, both samples have crack openings that are smaller than the computed traction-free profile. The results of the multicutting compliance experiments for the alumina specimen indicated a bridging-zone length of $L$ $\approx 2 \mathrm{~mm}$. Using the above results, bridging-stress distributions, $\sigma_{\mathrm{br}}(\mathrm{X})$, were calculated for both cases (Fig. 4). For alumina, the normalized distribution $\sigma_{\mathrm{br}}(\mathrm{X}) / \sigma_{\max }$ was computed directly from the multi-cutting compliance results using Eq. 1; the constant $\sigma_{\max }$ was determined to be $27.5 \mathrm{MPa}$ from the crack-opening data. For $5 \mathrm{ABC}-\mathrm{SiC}$, the value of $\sigma_{\max }$ and the exponent $n$ from Eq. 5 were determined to be $87.5 \mathrm{MPa}$ and 1.2, respectively.

\section{Discussion}

From the grain-bridging stress distributions in Fig. 4, bridging stress intensities, $K_{\mathrm{br}}$, were computed using $(12,13)$ :

$$
K_{\mathrm{br}}=\int_{0}^{a} h(x, a) \sigma_{\mathrm{br}}(x) d x
$$

giving values of $K_{\mathrm{br}}=1.8$ and $4.0 \mathrm{MPa} \sqrt{\mathrm{m}}$ for alumina and $5 \mathrm{ABC}-\mathrm{SiC}$, respectively. Corresponding values of the near-tip driving force, $K_{\text {tip }}$, were then determined from:

$$
K_{\text {tip }}=K_{\text {app }}-K_{\text {br }}
$$

giving 1.2 and $2.2 \mathrm{MPa} \sqrt{\mathrm{m}}$ for alumina and $5 \mathrm{ABC}-\mathrm{SiC}$, respectively. To assess whether these values are reasonable, we assume that crack advance occurs when $K_{\text {tip }} \geq K_{\mathrm{o}}$, where $K_{\mathrm{o}}$ is the intrinsic stress intensity required for crack advance. At the fatigue threshold, this condition is presumed to be met at the peak of the loading cycle, i.e., when $K_{\max \text {,tip }}=K_{\mathrm{o}}$. For the present fatigue cracks, the applied loading corresponds to a level roughly $10-20 \%$ below the value of 
$K_{\max }$ at the fatigue threshold; thus, this estimated value of $K_{\text {tip }}$ should be lower than the actual value of $K_{\mathrm{o}}$. Based on this result, a range may be placed on $K_{\mathrm{o}}$ by assuming the remaining $10-$ $20 \%$ of stress intensity necessary for crack advance is added to $K_{\text {tip }}$ either by: i) the remaining additional load raises $K_{\text {tip }}$ and $K_{\text {br }}$ proportionally, thus giving $K_{\mathrm{o}}=1.4-1.5 \mathrm{MPa} \sqrt{\mathrm{m}}$ for alumina and $2.5-3.0 \mathrm{MPa} \sqrt{\mathrm{m}}$ for $5 \mathrm{ABC}-\mathrm{SiC}$, or ii) $K_{\mathrm{br}}$ is assumed to saturate and the remaining additional load increases only $K_{\text {tip }}$, giving $K_{\mathrm{o}}=1.5-1.8 \mathrm{MPa} \sqrt{\mathrm{m}}$ for alumina and $3.0-3.7$ $\mathrm{MPa} \sqrt{\mathrm{m}}$ for $5 \mathrm{ABC}-\mathrm{SiC}$ (i.e., an upper-bound estimate). Combining these values gives estimates of the intrinsic toughness of $K_{\mathrm{o}}=1.6 \pm 0.2 \mathrm{MPa} \sqrt{\mathrm{m}}$ for alumina and $3.1 \pm 0.6 \mathrm{MPa} \sqrt{\mathrm{m}}$ for $5 \mathrm{ABC}-\mathrm{SiC}$. Since failure occurs primarily intergranularly in both cases, $K_{\mathrm{o}}$ should correspond nearly with the grain-boundary toughness, and should be lower than values for single crystals.

Sapphire is reported to have a toughness ranging from $K_{\mathrm{c}} \approx 2.2$ to $2.4 \mathrm{MPa} \sqrt{\mathrm{m}}$ for various crystallographic planes, except near (0001) which does not crack (17-19). As these $K_{\mathrm{c}}$ values for even the weakest sapphire planes exceed $K_{\mathrm{o}}$ for the alumina, the computed values of $K_{0}$, and correspondingly $K_{\mathrm{br}}$, in the present study appear to be reasonable (Fig. 1a). This level of $K_{\mathrm{o}}$ for the present alumina, which has some $\mathrm{Ca}$ adsorbed at the boundaries (5), is lower than several reported values, $1.8-2.6 \mathrm{MPa} \sqrt{\mathrm{m}}$, for purer materials $(12,20-22)$; this is as expected from the extensive intergranular fracture seen in the material (5) and the steadily rising R-curve for the AD995 alumina (Fig. 2a). This is also consistent with other observations that more intergranular fracture occurs in certain debased aluminas (23) and the expectation that such a reduced $K_{\mathrm{o}}$ yields higher plateau toughness values (24). Also shown in Fig. 1a are the measured values of $K_{\max }$ for the shortest fatigue cracks that propagated near threshold, with these values falling only slightly above $K_{0}$, as expected, due to their small degree of bridging. For $\mathrm{SiC}$, single crystal fracture data are limited but are in the range of $2.9-3.4 \mathrm{MPa} \sqrt{\mathrm{m}}(25)$, while the commercial $\mathrm{SiC}$ ceramic Hexoloy ${ }^{\circledR}$, which fails transgranularly, has been reported to fail at $K_{\mathrm{c}} \approx 2.5-3.0 \mathrm{MPa} \sqrt{\mathrm{m}}(26)$. The deduced estimate for the grain-boundary toughness of $5 \mathrm{ABC}-\mathrm{SiC}$ is similar to these values for grain fracture in $\mathrm{SiC}$ (Fig. 1b). Although ideally the grain-boundary value would be distinctly lower than that for grain fracture, due to the simplifying assumptions made for the $\mathrm{SiC}$ case, and the limited single crystal fracture data, the considerable overlap seen in Fig. $1 \mathrm{~b}$ is understandable. It is probable that further refinements in this technique will improve these estimates somewhat.

Fig. 2a clearly demonstrates short crack effects in this alumina in the form of faster growth rates, lower $\Delta K_{\mathrm{TH}}$ thresholds (versus long crack results), and V-shaped $d a / d N-\Delta K$ behavior for fatigue cracks with $\Delta a_{\mathrm{f}}<2 \mathrm{~mm}$. Qualitatively, the transient short crack behavior can be rationalized by considering that the grain-bridging zones for short cracks have yet to reach the steady-state size for long cracks, where bridges are created and "exhausted" at an equal rate; indeed, $2 \mathrm{~mm}$ corresponds well with the measured bridging-zone length for a long fatigue

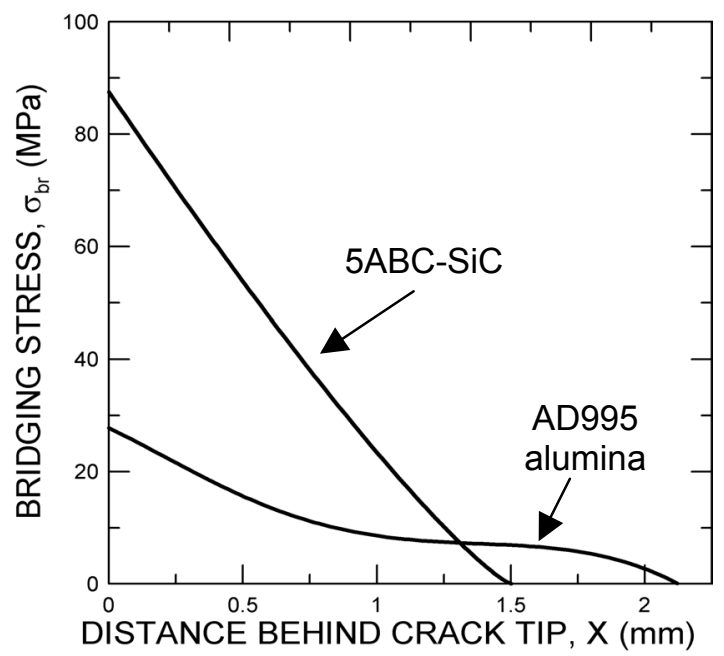

Figure 4: Bridging stress distributions for samples loaded to $80-90 \%$ of $K_{\max }$ at the long crack fatigue threshold. crack. Additionally, the V-shaped crack-growth curve observed for short cracks is attributed to fact that although the applied driving force is increasing with increasing crack length, the cracktip shielding due to grain bridges initially increases at a faster rate, causing the effective crack-tip driving force to decrease; this leads to an initial reduction in crack-growth rates. After further growth, however, a steady-state is reached and the growth rates match those of long cracks.

While these explanations have been used to rationalize short crack effects for a wide range of materials $(6,27,28)$, there have been few reports of quantitative measurements of this reduced role of shielding to confirm this phenomenon for the fatigue of ceramics. Using $K_{\mathrm{o}}$ values estimated 
above, and assuming that at the fatigue threshold $K_{\text {max,tip }}=K_{0}$, an estimate can be made for the initiation condition for growth of short fatigue cracks with no bridging. For a load ratio of $R=$ 0.1 , this corresponds to effective fatigue thresholds of, respectively, $\Delta K_{\text {eff,TH }}=1.4 \pm 0.2$ and 2.8 $\pm 0.5 \mathrm{MPa} \sqrt{\mathrm{m}}$ for this alumina and $5 \mathrm{ABC}-\mathrm{SiC}$ in the absence of bridging; these ranges are plotted in Fig. 2 along with the actual measured fatigue data.

It is apparent from Fig. 2 that when the long crack data are adjusted for crack bridging by characterizing the growth rates in terms of the deduced effective (near-tip) driving force, the $\Delta K_{\mathrm{TH}}$ thresholds are shifted to lower values. For alumina, this range falls only slightly below the shortest crack results, which correspond to the first $60 \mu \mathrm{m}$ of growth at $\Delta K \approx 1.8 \mathrm{MPa} \sqrt{\mathrm{m}}$, and additionally below sapphire results taken from ref. (29) (Fig. 2). Accordingly, it is expected that the effective threshold of $\Delta K_{\text {eff,TH }}=1.4 \pm 0.2 \mathrm{MPa} \sqrt{ }$ m determined in this study is a reasonable estimate of the worst-case, short crack behavior in AD995 alumina. Such agreement in the results reaffirm the notion that short crack effects may be attributed to a lack of grain bridging and provides validity to the preliminary values of the worst-case fatigue threshold deduced for $5 \mathrm{ABC}-\mathrm{SiC}$, where no short crack testing has been possible. These levels may be considered as the most conservative available estimates of the stress intensity to cause cracking in these ceramics. However, they do apply specifically to functionally short cracks, and thus do not take into account microstructurally-small crack effects; correspondingly, they should only be used when a reasonable statistical sampling of the microstructure is achieved.

\section{Conclusions}

Based on experiments to quantify the effect of grain bridging on fatigue-crack propagation behavior in AD995 alumina and 5ABC-SiC ceramics, the following conclusions are made:

1. Short fatigue cracks in the alumina clearly exhibited lower fatigue resistance over the first 2 $\mathrm{mm}$ of growth, in the form of lower fatigue thresholds and higher growth rates at the same applied driving force; thereafter, the data merged with that of long cracks.

2. By initiating very short cracks $(<60 \mu \mathrm{m})$ from micronotches $(\rho \approx 15 \mu \mathrm{m})$, crack growth in the alumina was observed at the lowest driving forces found, i.e., at $\Delta K=1.7 \mathrm{MPa} \sqrt{\mathrm{m}}$.

3. The observed transient behavior of short cracks in the alumina was attributed to a smaller degree of crack bridging due to their limited crack wakes. When the contribution of grain bridging was quantitatively estimated and removed from the applied driving force, a worstcase fatigue threshold for a load ratio of $R=0.1$ was determined, in terms of the near-tip stress intensity, as $\Delta K_{\text {eff,TH }}=1.4 \pm 0.2 \mathrm{MPa} \vee \mathrm{m}$, below which cracks of all sizes could not be observed to propagate.

4. The intrinsic, near-tip, driving force necessary for crack advance in the alumina was estimated to be $K_{\mathrm{o}}=1.6 \pm 0.2 \mathrm{MPa} \sqrt{\mathrm{m}}$. This is proposed to correspond to the lowest point on the R-curve for very short cracks.

5. Although short crack fatigue behavior has not been attainable to date in $5 \mathrm{ABC}-\mathrm{SiC}$, where the bridging zones are much smaller than for AD995 alumina, the present methodology allowed a preliminary estimate to be made for a worst-case fatigue threshold $(R=0.1)$ of $\Delta K_{\text {eff,TH }}=2.8 \pm 0.5 \mathrm{MPa} \sqrt{\mathrm{m}}$, below which both long and short cracks are expected not to propagate. Additionally, grain-boundary initiation toughness for 5ABC-SiC was estimated to be $K_{\mathrm{o}}=3.1 \pm 0.6 \mathrm{MPa} \sqrt{\mathrm{m}}$; while this seems somewhat high, these results are preliminary and are expected to improve with further data and technique refinement.

Acknowledgments: This work was supported by the Office of Science, Office of Basic Energy Sciences, Division of Materials Sciences and Engineering of the U.S. Department of Energy under Contract No. DE-AC0376SF00098. Thanks are due to Prof. L. C. DeJonghe, Dr. J. M. McNaney, P. A. Greaney, Dr. E. A. Stach and D. Ah Tye for discussion and assistance. 


\section{References}

1. R. O. Ritchie and S. Suresh, "The fracture mechanics similitude concept: questions concerning its application to the behavior of short fatigue cracks," Mater. Sci. Eng., 57 (2) (1983), L27-L30.

2. P. L. Swanson, C. J. Fairbanks, B. R. Lawn, Y.-W. Mai and B. J. Hockey, "Crack-interface grain bridging as a fracture resistance mechanism in ceramics: I, Experimental study on alumina," J. Am. Ceram. Soc., 70 (4) (1987), 279-289.

3. R. W. Steinbrech, F. Deuerler, A. Reichl and W. Schaarwächter. "Correlation of crack opening displacement and crack resistance curve of alumina," Science of Ceramics, eds. D. Taylor, R. W. Davidge, R. Freer and D. T. Livey The Institute of Ceramics, Shelton, Stoke-on Trent, Staffs., UK, 1987), 659-664.

4. S. Suresh and R. O. Ritchie, "Propagation of short fatigue cracks," Int. Metals Rev., 29 (6) (1984), 445-476.

5. J. J. Kruzic, R. M. Cannon and R. O. Ritchie, "Fatigue crack growth behavior of short cracks in polycrystalline alumina: Quantification of the role of grain bridging," J. Am. Ceram. Soc., (2002), in review.

6. R. O. Ritchie and W. Yu. "Short crack effects in fatigue: a consequence of crack tip shielding," Small Fatigue Cracks, eds. R. O. Ritchie and J. Lankford TMS-AIME, Warrendale, PA, 1986), 167-189.

7. C. J. Gilbert, Y. S. Han, D. K. Kim and R. O. Ritchie, "Anomalous cyclic fatigue-crack propagation behavior of small cracks in monolithic, grain bridging ceramics," Ceram. Inter., 26 (2000), 721-725.

8. W. F. Deans and C. E. Richards, "A simple and sensitive method of monitoring crack and load in compact fracture mechanics specimens using strain gages," J. Test. Eval., 7 (3) (1979), 147-154.

9. C. J. Gilbert, J. M. McNaney, R. H. Dauskardt and R. O. Ritchie, "Back-face strain compliance and electricalpotential crack length calibrations for the disk-shaped compact-tension DC(T) specimen," J. Test. Eval., 22 (2) (1994), 117-120.

10. A. N. Palazotto and J. G. Mercer, "Crack considerations in a notched compact tension specimen," Eng. Fract. Mech., 37 (3) (1990), 473-492.

11. F. H. Wittmann and X. Hu, "Fracture process zone in cementitious materials," Int. J. Fract., 51 (1991), 3-18.

12. T. Fett, D. Munz, J. Seidel, M. Stech and J. Rödel, "Correlation between long and short crack R-curves in alumina using the crack opening displacement and fracture mechanical weight function approach," J. Am. Ceram. Soc., 79 (5) (1996), 1189-1196.

13. T. Fett and D. Munz, Stress Intensity Factors and Weight Functions. (Southampton, UK: Computational Mechanics Publications, 1997), 408.

14. T. Fett, C. Mattheck and D. Munz, "On the calculation of crack opening displacement from the stress intensity factor," Eng. Fract. Mech., 27 (1987), 697-715.

15. R. M. L. Foote, Y.-M. Mai and B. Cotterell, "Crack growth resistance curves in strain-softening materials," J. Mech. Phys. Sol., 34 (6) (1986), 593-607.

16. C. J. Gilbert and R. O. Ritchie, "On the quantification of bridging tractions during subcritical crack growth under monotonic and cyclic fatigue loading in a grain-bridging silicon carbide ceramic," Acta Mater., 46 (2)

(1998), 609-616.

17. S. M. Wiederhorn, "Fracture of sapphire," J. Am. Ceram. Soc., 52 (9) (1969), 485-491.

18. S. M. Wiederhorn, B. J. Hockey and D. E. Roberts, "Effect of temperature on the fracture of sapphire," Phil. Mag., 28 (4) (1973), 783-796.

19. M. Iwasa and R. C. Bradt. "The fracture toughness of single crystal alumina," Structure and properties of MgO and $\mathrm{Al}_{2} \underline{\mathrm{O}}_{3}$ ceramics, ed. W. D. Kingery (Cambridge, Massachusetts: American Ceramic Society, Columbus, $\mathrm{OH}$, 1984), 767-779.

20. O. Raddatz, G. A. Schneider and N. Claussen, "Modeling of R-curve behavior in ceramic/metal composites," Acta Mater., 46 (18) (1998), 6381-6395.

21. O. Raddatz, G. A. Schneider, W. Mackens, H. Voss and N. Claussen, "Bridging stresses and R-curves in ceramic/metal composites," J. Eur. Ceram. Soc., 20 (13) (2000), 2261-2273.

22. T. Fett, "Crack-tip toughness from wide-range COD measurements," Int. J. Fract., 114 (4) (2002), L29-32.

23. C. A. Powell-Dogan and A. H. Heuer, "Microstructure of $96 \%$ alumina ceramics. III. Crystallization of highcalcia boundary glasses," J. Am. Ceram. Soc., 73 (12) (1990), 3684-3691.

24. R. F. Cook and A. G. Schrott, "Calcium segregation to grain boundaries in alumina," J. Am. Ceram. Soc., 71 (1) (1988), 50-58.

25. J. L. Henshall and C. A. Brookes, "The measurement of $K_{\mathrm{IC}}$ in single crystal SiC using the indentation method," J. Mater. Sci. Lett., 4 (6) (1985), 783-786.

26. C. J. Gilbert, J. J. Cao, L. C. De Jonghe and R. O. Ritchie, "Crack-growth resistance-curve behavior in silicon carbide: small versus long cracks," J. Am. Ceram. Soc., 80 (9) (1997), 2253-2261.

27. A. A. Steffen, R. H. Dauskardt and R. O. Ritchie, "Cyclic fatigue life and crack-growth behavior of microstructurally small cracks in magnesia-partially-stabilized zirconia ceramics," J. Am. Ceram. Soc., 74 (6) (1991), 1259-1268.

28. J. J. Kruzic, J. P. Campbell and R. O. Ritchie, "On the fatigue behavior of $\gamma$-based titanium aluminides: Role of small cracks," Acta Mater., 47 (3) (1999), 801-816. 
29. B. Asoo, J. M. McNaney, Y. Mitamura and R. O. Ritchie, "Cyclic fatigue-crack propagation in sapphire in air and simulated physiological environments," J. Biomed. Mater. Res., 52 (2000), 488-491. 